\title{
EXPERIÊNCIAS SIGNIFICATIVAS EM ARTES VISUAIS NA EDUCAÇÃO INFANTIL
}

\author{
EXPERIENCIAS SIGNIFICATIVAS EN ARTES VISUALES EN EDUCACIÓN \\ INFANTIL
}

\author{
RELEVANT EXPERIENCES OF VISUAL ARTS IN EARLY CHILDHOOD \\ EDUCACION
}

\author{
Simone Aparecida MARTINS ${ }^{1}$ \\ Maria de Fatima da Silva Costa Garcia de MATTOS ${ }^{2}$
}

RESUMO: Este estudo investigou a relevância das experiências estéticas na formação do professor atuante na Educação Infantil, no sul do estado de Minas Gerais. Refletimos sobre a necessidade e a importância do ensino por meio de experiências estéticas significativas pautadas pela imaginação criadora, a sensibilidade, a educação do olhar, o protagonismo infantil e a relação da arte na educação como expressão vital para a criança na formação das linguagens plástica e visual. A pesquisa de abordagem qualitativa utilizou a técnica do grupo focal com oito professoras, sobre o qual os dados coletados foram analisados por meio da Análise de Conteúdo. Os resultados obtidos comprovaram o descompasso existente entre a teoria e as metodologias contemporâneas, em relação às práticas vigentes. Constatou-se que o professor necessita vivenciar experiências estéticas a fim de ampliar o olhar para além do estereótipo, e possibilitar que as crianças exercitem o potencial criativo com liberdade de expressão e imaginação.

PALAVRAS-CHAVE: Artes visuais. Educação infantil. Formação de professor.

RESUMEN: Este estudio investigó la relevancia de las experiencias estéticas en la formación del profesor activo en la Educación Infantil, en el sur del Estado de Minas Gerais. Reflexionamos sobre la necesidad y la importancia de la enseñanza a través de experiencias estéticas significativas guiadas por la imaginación creativa, la sensibilidad, la educación de la mirada, el protagonismo infantil, la producción autoral infantil y la relación del arte en la educación como expresión vital para los niños en formación de lenguajes visuales y plásticos. La investigación con enfoque cualitativo utilizó la técnica de grupos focales con ocho profesores, sobre lo cual, de los datos recolectados se analizaron a través del Análisis de Contenido. Los resultados obtenidos evidenciaron la brecha entre la teoría y las metodologías contemporáneas, en relación con las prácticas actuales. Se encontró que el docente necesita experimentar experiencias estéticas para ampliar la mirada más allá del estereotipo y permitir que los niños ejerzan su potencial creativo con libertad de expresión e imaginación.

1 Centro Universitário da Fundação Educacional Guaxupé (UNIFEG), Guaxupé - MG - Brasil. Docente do Curso de Pedagogia. Mestrado em Educação (CUML). ORCID: https://orcid.org/0000-0002-6614-4811. E-mail: symonimuzamba@yahoo.com.br

${ }^{2}$ Centro Universitário Moura Lacerda (CUML), Ribeirão Preto - SP - Brasil. Professora e Pesquisadora no Programa de Pós-Graduação em Educação (PPGE). Doutorado em Artes (ECA/USP). ORCID: https://orcid.org/ 0000-0001-6275-8595. E-mail: mffmattos@gmail.com 
PALABRAS CLAVE: Artes visuales. Educación infantil. Formación del profesor.

ABSTRACT: This study investigated the relevance of aesthetics experiences in the education of teachers working in Early Childhood Education, in the south of the State of Minas Gerais. We reflected on the need and importance of teaching through significant aesthetics experiences guided by creative imagination, sensitivity, education of the gaze, child protagonism, child authorial production and the relationship of art in education as a vital expression for children in formation of visual and plastic languages. A qualitative research was carried out with a focus group of eight female professors. To collect the data, and the result was analyzed using Content Analysis. The results obtained proved the gap between contemporary theory and methodologies, in relation to current practices. It was found that the teacher needs to experience aesthetic experiences in order to expand the look beyond the stereotype and enable children to exercise their creative potential with freedom of expression and imagination.

KEYWORDS: Visual arts. Child education. Teacher education.

\section{Introdução}

Em um modelo de educação focado em resultados concretos e no desenvolvimento cognitivo, que tenta separar razão e emoção, parece-nos soar estranho utilizarmos a palavra sensibilidade. Duarte Junior (2012), mostra que em certo sentido estamos vivendo numa civilização racionalista, na qual se pretende separar a razão dos sentimentos e das emoções. Para esse autor, no ambiente escolar, a separação entre razão e emoção não deve ser somente mantida, como também estimulada. "Dentro de seus muros o aluno deve penetrar despindo-se de toda e qualquer emotividade. Sua vida, suas experiências não contam" (DUARTE JUNIOR, 2012, p. 32).

A educação pela Arte, tese de doutoramento de Herbert Read (1942), apresenta um vasto conjunto de conceitos educacionais e discorre sobre problemas da arte e da formação humana. Para ele, embora pareça evidente que em uma sociedade democrática o objetivo da educação deva ser a promoção do crescimento individual, vários problemas surgem quando começamos a considerar quais métodos adotar para esse fim (READ, 2016). Assim, acredita o autor, ser um ajustamento complexo alinhar sentimentos e emoções subjetivas ao mundo objetivo.

A educação da sensibilidade estética é de fundamental importância. É uma forma de educação da qual apenas traços rudimentares são encontrados nos sistemas educacionais do passado, e que só aparece de maneira muito acidental e arbitrária na prática educativa de hoje. Deve ficar claro, desde o 
princípio, que o que tenho em mente não é apenas a "educação artística" enquanto tal, o que seria mais adequadamente chamado de educação visual ou plástica: a teoria a ser apresentada compreende todos os modos de autoexpressão, literária e poética (verbal), bem como musical ou auricular, e constitui uma abordagem integral da realidade que deveria ser chamada de educação estética - a educação dos sentidos nos quais a consciência e, em última instância, a inteligência e o julgamento do indivíduo estão baseados (READ, 2016, p. 8, grifos do autor).

A educação pela arte ou por meio da arte, proposta pelo autor, dialoga com o conceito de desenvolvimento integral do ser humano, o qual valoriza os sentimentos e as emoções. Ao ressaltar o valor educativo da arte para a educação, ele define que devemos iniciar por estabelecer o conceito de artes como oriundo de um processo orgânico da evolução do homem. Para Buoro (2000), refletir sobre a função da imaginação criadora é procurar compreender como os processos criativos transformam a humanidade. Ao se perpassar pela história e pela trajetória da evolução da espécie humana, é impensável conceber todas as realizações, seja no campo da arte ou no da ciência, sem destacar o papel dos processos imaginativos e criativos.

Ana Mae Barbosa (2010, p. 12) argumenta:

Trata-se de uma experiência com o mundo empírico, com a cultura e a sociedade personalizada pelo processo de gerar significado. [...] Essa dubiedade da arte torna-a valiosa na educação. Em arte não há certo ou errado, mas sim o mais ou menos adequado, o mais ou menos significativo, o mais ou menos inventivo.

Para a criança, a arte é uma forma de comunicação e expressão. Vygotski (2009), ao discorrer sobre a imaginação criadora, diz que os primeiros pontos de apoio que a criança encontra para o que será sua criação futura são o que vê e o que ouve, acumulando instrumentos de aprendizagem que mais tarde serão usados nas construções de sua fantasia. Assim, elas são chamadas por aquilo que lhes interessa, por uma curiosidade em movimento.

Read (2016) diz que as percepções resultam em imagens, as sensações em sentimentos, e estes são materiais elementares para construirmos o nosso conceito do mundo e o nosso comportamento no mundo. Entendemos, por essa via, que o sentido da educação é assistir a criança nesse processo de aprendizagem e desenvolvimento humano, visto que esse desenvolvimento está diretamente relacionado à diversidade de experiências que ela tem oportunidade de vivenciar. Experiências que dependem do contexto social, familiar e escolar no qual ela está inserida.

Segundo Iavelberg (2017), a escola é uma oportunidade ímpar para o contato com a arte nos anos iniciais da Educação Básica (creches e pré-escolas). Para a autora, no espaço 
escolar as crianças podem criar, aprender e desenvolver sua arte por meio de experiências planejadas pelos professores, pelas escolhas que fazem dos materiais oferecidos e pela interação com os colegas. Cada criança é um universo potente de expressão, conforme indica a discussão empreendida pela autora, que em continuidade oferece alguns pontos de partida para o professor criar ações poéticas e momentos de interação. "É necessário compreender a importância do incentivo à autonomia e à investigação da criança, por meio da promoção de seu protagonismo criador, apoiando-a nas artes, nas demais áreas da educação escolar e na vida" (IAVELBERG, 2017, p. 35).

\section{Práticas pedagógicas em artes visuais na primeira infância}

Quem ensina arte na Educação Infantil na maioria das escolas públicas do sul de Minas Gerais é o professor generalista, formado nos cursos de Magistério ou Pedagogia. De acordo com Barbosa (2017, p. 17), "até hoje perdura a dificuldade de definições do que é importante se aprender para ensinar arte e qual deve ser a preparação dos professores para realizar a complexa inter-relação entre Arte e Pedagogia”. De fato, para Martins, Picosque e Guerra (2009, p. 11), “uma série de desvios vem comprometendo o ensino da arte. Ainda é comum essas aulas serem confundidas com lazer, terapia, descanso das aulas 'sérias', o momento para fazer a decoração da escola, das festas, comemorar determinada data cívica $[\ldots] "$.

No fim da década de 1980, houve um momento em que o ensino e a aprendizagem da arte consideraram que se aprende arte com arte, ou seja, partindo do pressuposto de que é necessário conhecer a produção social, histórica e cultural das artes para compreender e fazer arte na escola. Essa proposta foi sistematizada pela professora Ana Mae Barbosa (1988) e, inicialmente, chamada de Metodologia Triangular.

No início dos anos de 1990, a citada pesquisadora, preocupada com a democratização do conhecimento da arte vinculado a uma educação descontextualizada, percebeu a necessidade de investigar sobre o processo histórico do ensino para nele intervir conscientemente. Apresentou um posicionamento teórico-metodológico que ficou conhecido como Proposta Triangular ou Abordagem Triangular, que intencionava à melhoria do ensino de arte, tomando por base um trabalho pedagógico integrador.

Nesse sentido, convictos desse pensamento, afirmamos que, para acontecer uma aprendizagem significativa nas linguagens artísticas, precisamos da correta apreciação da história e do fazer artístico contextualizado desde a primeira infância. 
Para Barbosa (2014, p. 118),

[...] é importante repetir que o ensino pós-moderno de arte que implica contexto e análise interpretativa, integrados ao trabalho plástico, não é uma reação contra as conquistas do modernismo, mas uma ampliação dos princípios de expressão individual que marcaram a modernização do ensino de arte.

Assim, significa manter as conquistas expressivas do modernismo e ampliar as possibilidades do ensino de arte e sua conceituação como cultura.

Quando o aluno observa obras de arte e é estimulado e não obrigado a escolher uma delas como suporte de trabalho plástico, a sua expressão individual se realiza da mesma maneira que se organiza quando o suporte estimulador é a paisagem que ele vê̂ ou a cadeira de seu quarto. [...] O importante é que o professor não exija representação fiel, pois a obra observada é suporte interpretativo e não modelo para os alunos copiarem. Assim, estaremos ao mesmo tempo preservando a livre expressão, importante conquista do modernismo, e nos tornando contemporâneos (BARBOSA, 2014, p. 118).

\section{A Pesquisa}

Realizamos esta pesquisa durante o Mestrado em Educação no Programa de PósGraduação Strictu Senso do Centro Universitário Moura Lacerda, no ano de 2018, com o propósito de investigar a relevância das experiências estéticas em arte na formação inicial. Em outras palavras, pretendíamos investigar a necessidade e a importância do ensino das Artes Visuais por meio de ações significativas, pautadas pela imaginação criadora, pela sensibilidade, pela educação do olhar, pelo protagonismo infantil, pela produção autoral e pela relação da arte na educação como expressão vital para a criança na formação das linguagens plástica e visual.

Metodologicamente, adotamos a abordagem qualitativa utilizando a técnica do grupo focal. Convidamos algumas professoras da rede pública de uma cidade interiorana do sul de Minas Gerais para colaborarem com a pesquisa, e pudemos analisar as contribuições de oito docentes sobre os conhecimentos artísticos presentes na formação inicial do pedagogo, bem como suas práticas pedagógicas em artes visuais em uma sala de aula na Educação Infantil.

Durante os encontros do grupo focal, quisemos experenciar a afirmação de Meira (2009) e, primeiramente, propusemos às docentes explorar o sentido e a sensação da experiência estética frente à obra de arte. 
A experiência estética coloca a cognição em permanente desconstrução e reconstrução, pela vulnerabilidade aos acontecimentos, estados de espírito, relações com a cultura, saberes múltiplos vindos do corpo e de abstrações, além do que a mente elabora a partir de paisagens do corpo, da memória e da ficção. [...] uma experiência estética envolve as vivências e as transformações sensíveis e cognitivas que um sujeito elabora a partir dessas vivências. (MEIRA, 2009, p. 32)

Nas últimas décadas, ampliaram-se os estudos e, consequentemente, os dados referentes ao desenvolvimento infantil. Desponta uma urgente necessidade de rever e adequar o processo educativo das crianças na Educação Infantil a fim de favorecer possibilidades reais de aprendizagem e de desenvolvimento. No que se refere às linguagens artísticas, elas deixam de ser um fim para se tornarem um meio, respeitando e valorizando a experiência dessa etapa com todas as nuances simbólicas. Conforme Barbosa (2014, p. 5),

se pretendemos uma educação não apenas intelectual, mas, principalmente, humanizadora, a necessidade da arte é ainda mais importante para desenvolver a percepção e a imaginação, para captar a realidade circundante e desenvolver a capacidade criadora necessária à modificação desta realidade.

Além do mais, é necessário ressignificar as atividades "artísticas", pois, de complementares que eram, hoje nós as percebemos como centrais no desenvolvimento dessa fase da Educação Infantil. A partir da experiência no cotidiano, elas enriquecem a imaginação e a percepção, propiciando às crianças a oportunidade de construção de sentido por meio do movimento, da linguagem e das imagens. Ostetto (2011, p. 4) aponta que, "de modo geral, no campo educacional, tomamos um rumo diverso e caminhamos amparados pelas certezas pedagógicas, um porto seguro das regras e modos de fazer com medo do desconhecido, do que não podemos controlar, do campo do afeto, da fantasia e da sensibilidade".

Talvez seja essa inabilidade em lidarmos com o campo das incertezas, das descobertas, dos questionamentos do ser plural, o principal motivo da dificuldade das escolas e creches para lidar com a poética da vida presente na linguagem da criança. Torna-se preferível caminhar por terrenos conhecidos, seguir modelos, estabelecer regras e limites para a criação, exigir a perfeição vista pelo olhar do adulto a lançar-se em busca de novas propostas, da imaginação e da experimentação.

\section{Linguagem pictórica: a expressão da criança}


Desde a pré-história, os seres humanos criaram formas visuais e utilizaram símbolos para representar o seu modo de ser e de viver. As imagens desenhadas nas cavernas são as primeiras referências da existência do homem.

A função simbólica é o centro do processo de ensino e aprendizagem das crianças, pois elas constroem signos para os objetos com que lidam, para as suas ações e os seus conceitos. As linguagens, verbal, escrita e pictórica são fundamentais na representação do sistema simbólico, na primeira infância como fonte de expressão, comunicação e desenvolvimento integral da criança. Barbosa (2010, p. 99) diz que "dentre as artes, as visuais, tendo a imagem como matéria-prima, tornam possível a visualização de quem somos, de onde estamos e de como sentimos".

Trabalhar com imagens e processos de criação artística e estética mobiliza saberes e operações complexas no manuseio da fantasia e de repertórios formativos. "O elemento expressivo que distingue a pintura das demais linguagens artísticas é a cor. Aquele que pinta imagina, em termos de cores, transparências, opacidades operando com os materiais utilizados para representar um efeito de luz" (CUNHA, 2014, p. 65). Vale lembrar que as crianças pequenas não desenham ou pintam com a finalidade de serem artistas, e sim, para se expressarem e se comunicarem. O desenho e a pintura são experiências que a criança vivencia e contam sobre ela, sobre seus pensamentos e suas fantasias ao criarem símbolos para representação. Para Dewey (2010, p. 92-93),

[...] a arte, portanto, prefigura-se nos próprios processos do viver. [...] A existência da arte é a prova concreta do que acabou de ser afirmado em termos abstratos. É a prova de que o homem usa os materiais e as energias da natureza com intenção de ampliar a própria vida. [...] A arte é a prova viva e concreta de que o homem é capaz de restabelecer, conscientemente e, portanto, no plano do significado, a união entre necessidade, impulso e ação, que é característica do ser vivo.

Há muitas questões como as que já mencionamos sobre a importância da linguagem pictórica no desenvolvimento da criança em artes visuais que precisam ser relacionadas ao conhecimento artístico e estético do professor. Ele deve pesquisar e conhecer a arte e se aperfeiçoar continuamente a fim de proporcionar possibilidades de experiências significativas que levem em consideração as necessidades das crianças.

\section{O grupo focal}


Grupo focal é a denominação de uma técnica de pesquisa qualitativa na qual o pesquisador reúne um conjunto de pessoas, o público-alvo de sua investigação, para coletar os dados para a sua pesquisa - é uma metodologia utilizada há muito tempo. Nos anos de 1970, o uso de grupos de discussão como fonte de informação foi comum em áreas particulares, a exemplo da pesquisa em comunicação. Segundo Gatti (2005), houve uma espécie de redescoberta dos grupos focais no início dos anos de 1980, momento em que cresceu a preocupação em adaptar essa técnica para o uso na investigação científica.

Segundo Powel e Single (1996 apud GATTI, 2005, p. 7), um grupo focal "é um conjunto de pessoas selecionadas e reunidas por pesquisadores para discutir e comentar um tema, que é objeto de pesquisa, a partir de sua experiência pessoal". De acordo com Iervolino e Pelicioni (2001, p. 115), “como técnica de pesquisa qualitativa, o grupo focal obtém dados a partir de reuniões em grupo, com pessoas que representam o objeto de estudo". Para os autores citados acima, a essência do grupo focal consiste justamente na interação entre os participantes e o pesquisador, que objetiva colher dados a partir da discussão focada em tópicos específicos e diretivos.

Essa técnica é decorrente das diferentes formas de trabalho com grupos, como observação e entrevista. Como descreve Bernadete Gatti (2005, p. 9),

\footnotetext{
a pesquisa com grupos focais tem por objetivo captar, a partir das trocas realizadas no grupo, conceitos, sentimentos, atitudes, crenças, experiências e reações, processos e conteúdos cognitivos, emocionais, ideológicos, representacionais e coletivos. $\mathrm{O}$ grupo focal permite fazer emergir uma multiplicidade de pontos de vista e processos emocionais, pelo próprio contexto de interação criado, permitindo a captação de significados que poderiam ser difíceis de se manifestar em outros meios.
}

A autora acrescenta que a opção pelo grupo focal tem que estar integrada ao corpo da pesquisa e aos seus objetivos, atendendo ao referencial teórico utilizado e o ainda pretendido. Para Gatti (2005, p. 9), “a ênfase recai sobre a interação dentro do grupo e não em perguntas e respostas entre moderador e membros do grupo".

\section{Os sujeitos e o cenário}

Solicitou-se inicialmente à Secretaria Municipal de Educação autorização à atividade de formação de um grupo focal com algumas professoras e, somente após isso, as professoras e a escola foram comunicadas. A instituição marcou data e horário para que essas profissionais participassem do módulo semanal. No momento do convite, foi explicitado o 
objetivo da pesquisa e o da reunião a fim de que pudéssemos ter participantes voluntários. De acordo com Gatti (2005, p. 13), "o convite deve ser motivador, de modo que os que aderirem ao trabalho estejam sensibilizados tanto para o processo como para o tema geral a ser tratado, ou seja, a atividade do grupo focal deve ser atraente para os participantes".

Em um primeiro momento, todas as professoras demonstraram o desejo em participar, por se tratar de um tema interessante, mas justificaram que não tinham disponibilidade por causa de outros compromissos. Nesse dia, 12 professoras deixaram seus nomes à disposição das pesquisadoras. Na opinião de diversos autores, quando visamos abordar questões com maior profundidade, o grupo focal não pode ser nem grande, nem tão pequeno, ficando a variante entre 6 e 12 pessoas. Nesse sentido, o número de adesão das professoras ficou dentro do desejado. De modo geral, elas agradeceram e se mostraram lisonjeadas pela escola ter sido escolhida entre tantas outras. Para Gatti (2005, p. 13), "a participação num processo de grupo focal também pode propiciar um momento de desenvolvimento para os participantes, tanto nos aspectos comunicacionais, como nos cognitivos e afetivos".

O cenário escolhido para a pesquisa foi uma escola pública municipal de Educação Infantil localizada em uma cidade do sul de Minas Gerais, onde leciono desde 2008 e da qual, atualmente, encontro-me afastada por ocupar o cargo de Secretaria de Educação do Município de Muzambinho (MG). Os sujeitos do estudo foram oito professoras dessa instituição atuantes na Educação Infantil, com turmas na faixa etária entre 3 e 6 anos, sendo que as outras quatro declinaram do convite. O grupo focal nos permitiu compreender melhor o nível de conhecimento das professoras obtido nos cursos de Magistério e Pedagogia nessa região e a sua formação continuada, no que concerne à área de artes, bem como as suas práticas em sala de aula.

As participantes do grupo focal estão identificadas pela inicial do nome, pela idade, pela formação e pelo tempo de atuação em turmas de Educação Infantil.

Tabela 1 - Participantes do grupo focal

\begin{tabular}{|c|c|c|c|}
\hline INICIAL DO NOME & IDADE & FORMAÇÃO & TEMPO DE ATUAÇÃO \\
\hline C. & 28 & Pedagogia & 5 anos \\
\hline E. & 33 & Pedagogia & 6 anos \\
\hline F. & 62 & Magistério & 32 anos \\
\hline V. & 53 & Magistério & 22 anos \\
\hline Eu. & 42 & Magistério & 36 anos \\
\hline M.I. & 64 & Magistério & 20 anos \\
\hline R. & 55 & Magistério & 2 anos \\
\hline G. & 40 & Magistério & \\
\hline
\end{tabular}

Fonte: Elaborado pelas autoras 
Com o intuito de encontrarmos subsídios para identificar como os conhecimentos em arte adquiridos pelo professor na sua formação inicial contribuíram para uma prática criativa e sensível, que considerasse as potencialidades expressivas das crianças, constituímos um Grupo Focal e aplicamos para as professoras um questionário com questões semiestruturadas. No primeiro encontro com as participantes esclarecemos os objetivos da pesquisa e a ação, de acordo com a técnica do Grupo Focal.

O moderador do grupo focal nem sempre é o pesquisador, mas neste caso a mestranda/ pesquisadora foi a moderadora, apesar de seguir o princípio da não diretividade, ou seja, não explicitar suas opiniões e não inferir julgamentos sobre a opinião dos participantes. Gatti $(2005$, p. 9) coloca que o moderador "deverá fazer encaminhamentos quanto ao tema e fazer intervenções que facilitem as trocas, como também procurar manter os objetivos de trabalho do grupo". A função do moderador é criar condições para a discussão fluir a fim de que os participantes possam expor seus pontos de vista, analisar, fazer críticas e, dessa forma, abrir perspectivas dentro da temática para a qual foram convidados a discutir.

Assim, apresentamos a proposta da pesquisa e dividimos os encontros em cinco com 60 minutos cada. Os dois primeiros foram dedicados à leitura, ao debate e à reflexão dos textos selecionados, o terceiro e o quarto encontros à reflexão sobre a prática das artes visuais com experimentação de materiais, e o quinto às narrativas das propostas desenvolvidas com as turmas de Educação Infantil e ao mapeamento das ideias e do que cada membro do grupo apreendeu. Nesta pesquisa, a arte surge como um convite para revisitar as concepções e práticas com um novo olhar, descobrindo possibilidades e engendramentos nestas ações pedagógicas nas atividades com artes visuais na primeira infância.

Propusemos o texto Concepções e práticas artísticas na escola, de Celia Maria de Castro Almeida (2012), que inicialmente apresenta a questão: "Para que servem as artes na escola?". A partir dessa pergunta, começamos a leitura e a reflexão com o grupo. Fizemos um exercício de buscar as aulas de artes na memória. Após pequeno silêncio e troca de olhares, próprios da insegurança inicial, aos poucos as professoras perceberam que a questão proposta não era sobre os conceitos de certo ou errado, mas sobre interpretações e compreensão dos sentidos atribuídos à arte na Educação Infantil. A partir disso, as respostas surgiram naturalmente, em um ambiente dialógico e de muita troca. 
C: Leitura do mundo, expressão...

F: Autoconhecimento.

G: Sentimento.

$R$ : Bom, eu sou suspeita para falar (risos), mas acho que tudo que a gente faz se envolver a arte, a gente consegue muito, muito mais fácil.

F: Fica mais prazeroso...

R: Isso, fica mais prazeroso. Ih... mas eu acho que o que embaça é a pessoa pensar que precisa ser artista para ensinar arte, então vai se deixando isso muito a desejar.

M.I: Eu acho que desenvolve a percepção, né! Dos diferentes modos de pensar. (INFORMAÇÃO VERBAL) ${ }^{3}$

O texto de Almeida (2012), oferecido para a equipe do grupo focal, mostra que na opinião de muitos professores as artes têm um caráter utilitário, meramente instrumental, e esclarece em nota de rodapé que o artigo está fundamentado em registros de observações, entrevistas e questionários recolhidos em suas pesquisas sobre concepções e práticas de professores que atuam na Educação Infantil e nos níveis Fundamental e Médio, não sendo, portanto, dados de ficção, mas exemplos do que realmente ocorre no ensino de arte em algumas escolas. De acordo com Tourinho (2012, p. 32), "uma compreensão desses elementos (significados, processos, funções e valores) em relação à arte e seu ensino, em uma determinada sociedade, é indispensável para avaliarmos, criticamente, as razões pelas quais encontramos tantos mal-entendidos".

Ao compararmos as falas das docentes do grupo focal participantes desta pesquisa com as dos professores citados no texto referência (ALMEIDA, 2012), percebemos que há uma diferenciação, pois elas não relacionaram a importância da arte a um mero utilitarismo e às atividades. No entanto, percebemos uma contradição, apresentada anteriormente, quando então as professoras pesquisadas foram levadas pelo texto a refletir sobre "por que essas atividades são importantes e devem ser incluídas no currículo escolar?”. Perguntamos ainda: “É tranquilo para vocês argumentarem sobre a importância da arte na Educação Infantil?". O silêncio tomou conta do ambiente, houve uma troca de olhares e quase um consenso ao afirmarem não saber claramente a resposta.

R: Não... eu acho que noventa por cento de nós não sabemos.

$F:$ Ah... eu acho que noventa e nove por cento não vão saber.

Eu: Por que?

F: Eu acho assim... porque é uma coisa assim... Muitas vezes você faz porque tá ali para fazer. Você faz da melhor maneira que consegue. Eu não tenho conhecimento profundo em arte, não tive na minha formação. Eu procuro, eu leio, eu estudo, procuro enriquecer, mas falar que isso é assim, por isso e por isso, eu não sei, é muito difícil.

\footnotetext{
${ }^{3}$ Manifestações verbais obtidas no primeiro encontro do grupo focal ocorrido em 08 de maio de 2018.
} 
$R$ : A gente retrata o nosso aprendizado, porque na realidade a gente sabe fazer as técnicas.

E: A gente fica só nas técnicas. (INFORMAÇÃO VERBAL) ${ }^{4}$

Partindo da premissa de que ensinamos o que sabemos, ou seja, um conhecimento prévio adquirido, percebemos nas colocações das professoras a repetição do ensino modular por meio da diferenciação de técnicas, ou seja, uma reprodução da formação inicial que tiveram na Graduação.

Ao encerrarmos essa fase do grupo focal, observamos que todas as participantes demonstraram bastante interesse e apresentaram questões relevantes sobre a prática das artes visuais, especificamente, relatando a dificuldade encontrada em trabalhar com propostas significativas de pintura com crianças na faixa etária em que atuam, ou seja, na primeira infância.

Na etapa seguinte, discutimos o texto Leitura e releitura, de Analice Dutra Pillar (2012), escolhido por se tratar de uma referência teórica atualizada na reflexão sobre as recorrentes práticas de releituras de obras de arte nas escolas em geral. Pillar (2012) apresenta um estudo minucioso sobre a leitura de imagem e exemplifica as diferenças entre a cópia e a releitura, o que consideramos essencial para a formação de professores na área de artes. Durante esse encontro, apresentamos a imagem de uma criança com várias tintas e concentrada na sua ação criadora - como um disparador para possíveis leituras e interpretações sobre o tema que iríamos abordar. O nosso objetivo era de suscitar reflexões e outras possíveis leituras sobre a imaginação infantil, a liberdade de criar e a produção autoral das crianças no ambiente escolar, bem como confrontá-las com as práticas mutiladoras do processo criativo existentes em escolas de Educação Infantil. Finalizamos com o seguinte questionamento: "Qual leitura vocês fazem dessa imagem?”. Surgiram os seguintes comentários:

C: Que ela tem autonomia para pegar o que ela quer, para criar, você vê que ela está bem à vontade para criar, que é um ambiente que propicia esse tipo de atividade, porque, se não propiciasse, ela não teria essa postura de misturar as tintas, de pegar outras coisas, porque têm outras coisas. Vocể vê que ela está concentrada, parece que o ambiente favorece esse tipo de propostas.

$V:$ Bem livre, né...

G: É isso... tentando se expressar, né... (INFORMAÇÃO VERBAL) ${ }^{5}$

Em outras palavras, podemos dizer que a professora C., ao realizar a leitura da imagem, apontou a autonomia da criança como uma referência da liberdade de expressão e do

${ }^{4}$ Manifestações verbais obtidas no segundo encontro do grupo focal ocorrido em 22 de maio de 2018.

${ }^{5}$ Manifestações verbais obtidas no segundo encontro do grupo focal ocorrido em 22 de maio de 2018. 
movimento do corpo: "Ela está bem à vontade para criar". Referiu-se a um ambiente que propicia esse tipo de atividade e favorece o processo de criação com diversos materiais, destacando a concentração da criança como um fato que revelou seu interesse pela proposta. Isto nos fez refletir sobre o ambiente das nossas escolas infantis: quais as possibilidades de experiência e criação, liberdade e expressão autoral que há lá? Como mediadora, coloquei uma nova questão para o grupo: "A imagem suscita alguma inquietação em vocês?”:

$V$ : Ah... por não poder fazer isso em uma sala de aula... (INFORMAÇÃO VERBAL) $)^{6}$

A forma como a professora falou e sua expressão de decepção causaram risos em todo grupo. Ao retomarmos a questão, as outras docentes se posicionaram.

F: Porque se trabalhar ali fora no mural e sujar, a gente tem que limpar. Tem que ser canetinha e passar álcool para limpar.

$V$ : É, a gente tem que limpar, entendeu..

E: A mãe vai reclamar que a roupa está suja.

C: Eu acho que a mãe é o de menos, eu penso que o pior é a gente não poder propiciar esses momentos.

M.I: Vocề que pensa... as mães têm muita influência, têm poder...

C: Oh, nós temos 20 alunos, você não tem uma auxiliar, então você vai ter que auxiliar cada criança, até eles aprenderem... aí tem programa para cumprir. Então... (INFORMAÇÃO VERBAL) ${ }^{7}$

Observamos que a imagem provocou algumas inquietações no grupo, revelando algumas angústias. Sobre isso, encontramos em Pillar (2014, p. 10) que "o olhar de cada um está impregnado por experiências anteriores, associações, lembranças, fantasias, interpretações, etc. O que se vê̂ não é o dado real, mas aquilo que se consegue captar e interpretar acerca do que é visto, o que nos é significativo". Cabe aqui ressaltar que a maioria das escolas públicas da região do sul de Minas, inclusive a em questão, não possui sala ambiente ou ateliê para a realização de oficinas artísticas, o que pode indicar um obstáculo para que esse tipo de atividade criadora ocorra mais livremente.

Encerrando essa discussão, dividimos outra angústia colocada pelas professoras, a famosa prática das releituras. Afinal, "o ensino de arte, leitura e releitura têm sido uma prática amplamente difundida, sem que muitas vezes se compreenda o que está implicado nessas dimensões do conhecimento da arte" (PILLAR, 2014, p. 7).

${ }^{6}$ Manifestação verbal individual, de uma professora ocorrido em22 de maio de 2018.

${ }^{7}$ Manifestações verbais obtidas no segundo encontro do grupo focal ocorrido em 22 de maio de 2018. 
Essa prática recorrente em sala de aula foi uma apropriação errônea e equivocada da Abordagem Triangular, por parte dos professores, como podemos observar nas palavras de Barbosa (2014, p. 28):

Desde a primeira edição [do livro] não falo nem uma vez em releitura. Essa palavra aparecia nas edições anteriores a esta, somente nas legendas das imagens produzidas. Para demonstrar meu repúdio à ideia de que receito a releitura, substituí na presente edição a palavra por interpretação.

Pillar (2014, p. 14) explica, de forma bem clara, esse equívoco didático entre releitura e cópia:

Em nome da Proposta Triangular, muitos professores estão trabalhando releitura como cópia. Colocam uma obra de arte para os alunos copiarem. O que se quer com isto? Aprender as formas, o modo como o artista organizou a composição? Qual o nosso objetivo com esta atividade? Criticam-se as folhas mimeografadas para colorir e dá-se a obra de arte para copiar. Há uma grande distância entre releitura e cópia. A cópia diz respeito ao aprimoramento técnico, sem transformação, sem interpretação, sem criação. Já na releitura há transformação, interpretação, criação com base num referencial, num texto visual que pode estar explícito ou implícito na obra final. Aqui o que se busca que é a criação e não a reprodução de uma imagem.

Por fim, após a discussão do texto, aproveitamos para realizar uma atividade que explorou a materialidade de diversos suportes, texturas, tintas e pincéis, lembrando o comentário de Cunha (2014, p. 15): "Uma das maneiras de o adulto romper com suas formas cristalizadas é resgatar seu próprio processo expressivo, voltando a brincar com os materiais, não tendo medo de mostrar suas próprias descobertas formais, espaciais e colorísticas [...]”.

Figura 1 - Atividade de experimentação do grupo focal

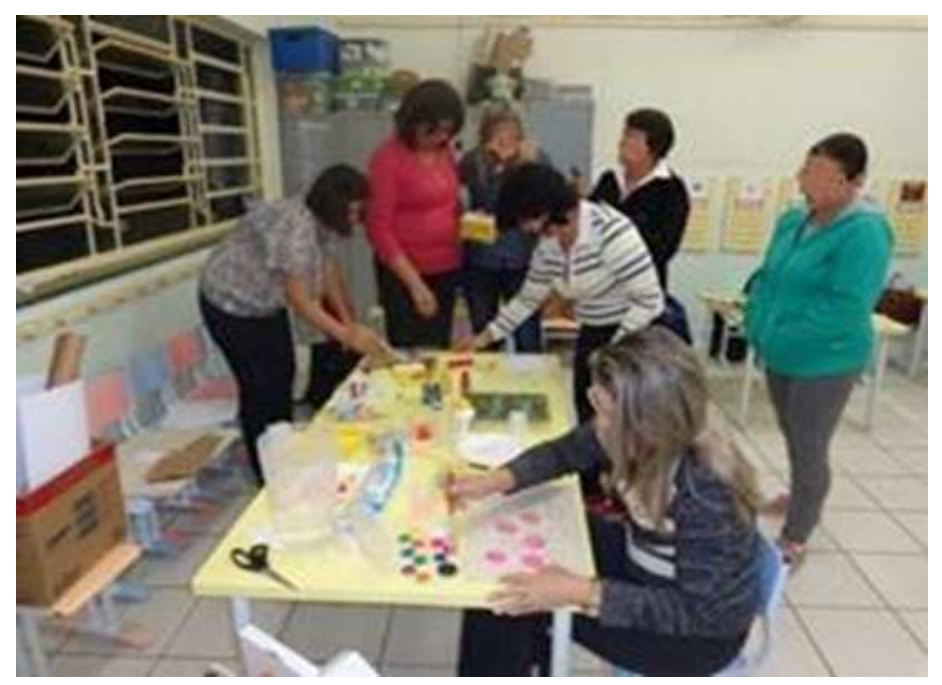


Fonte: Acervo das pesquisadoras

Do professor é esperado que o saber conceitual esteja articulado ao saber prático, para que ele consiga realizá-lo com maior destreza em sala de aula. No ensino de arte, é essencial que o professor viva a atividade de artes. Dewey (2010, p. 126) comenta que "a arte denota um processo de fazer ou criar" e, para ele, "a experiência estética, em seu sentido estrito, é vista como inerentemente ligada à experiência de criar".

\section{Dados obtidos das atividades realizadas após o grupo focal}

Para uma compressão mais ampla do processo realizado durante os encontros do grupo focal, entregamos às professoras um questionário com o intuito de resgatar o vivido e, também, convidá-las a criar uma proposta de atividade em artes visuais para suas turmas. No nosso último encontro, as professoras/participantes trouxeram o resultado executado pelas crianças, descrevendo não só a ação realizada como as percepções por elas obtidas, e selecionamos algumas para análise à luz do referencial teórico proposto pela pesquisa, ALMEIDA (2012), BARBOSA (2014), BUORO (2000), CUNHA (2014), DEWEY (2010), IAVELBERG (2017), PILLAR (2014).

A professora M.I. ( $1^{\circ}$ período, 4 anos) planejou uma proposta para a qual selecionou alguns artistas e imagens e sugeriu uma exploração coletiva. Assim, foi conduzindo o olhar das crianças para algumas características, como cor, formas, elementos conhecidos, semelhanças e diferenças entre as pinturas.

Figura 2 - Família de Gatos.

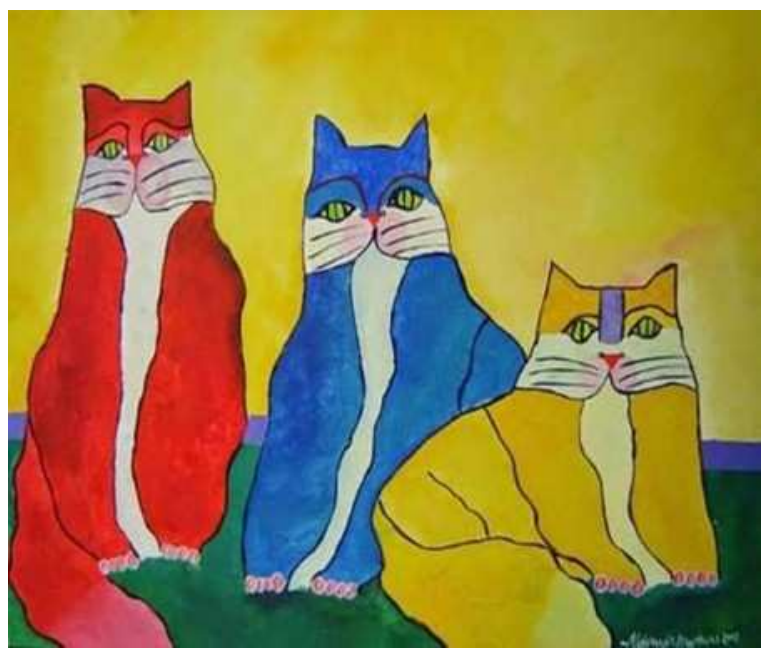


Fonte: Aldemir Martins (2003)

Figura 3 - O Galo

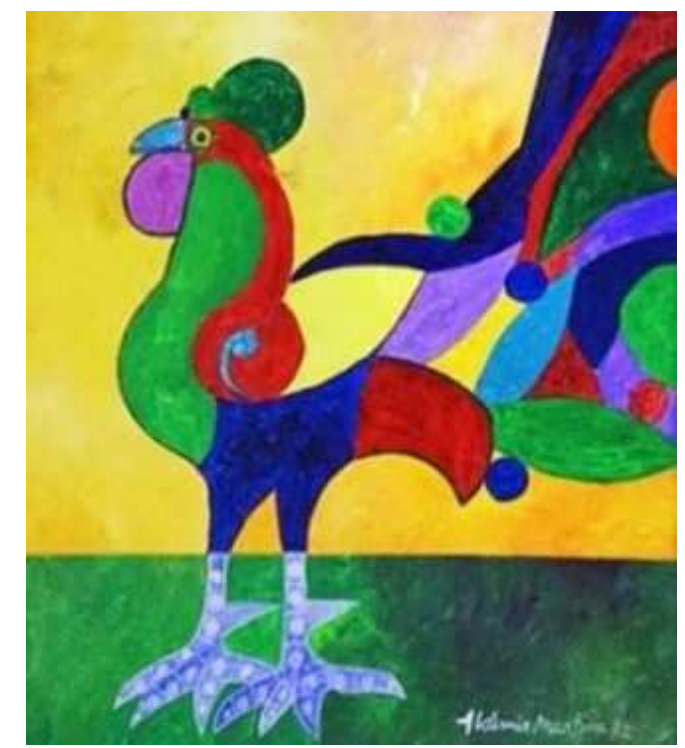

Fonte: Aldemir Martins (1997)

Nesse momento, pudemos afirmar que a professora, primeiramente, atuou por meio de uma curadoria, ao selecionar as imagens que levou para a turma, escolhendo aquelas que, como ela disse, "seriam mais do conhecimento deles", e depois como mediadora, ao instigar o pensamento, a percepção e a interpretação das obras dadas.

M.I.: Eu tirei algumas obras, tentei trazer aquilo que era do meio deles, $e$ eles adoram animais. Eu apresentei para eles, procurei ler com eles, o que eles estavam vendo, quais imagens identificavam, as cores, as formas, se o galo que eles conheciam era igual, se o nosso sol era vermelho, porque eles sempre usam amarelo ou laranja. Depois da leitura, da exploração da imagem, eu deixei que eles ficassem livres para pintar. Deixei as imagens à disposição, teve criança que foi olhar, outras não. Eu tentei arrumar material diferente, coloquei papelão, papel-cartão que eu ganhei das sobras da gráfica... O sulfite ninguém escolheu, coloquei pincéis grandes... Eu deixei o material livre para eles usarem, tinha canetinha, tinha pincel, cola colorida, tinha tinta. Eu tive que ficar por conta desse canto, tamanho o desespero das crianças para realizar a atividade, eles adoram mexer com tinta. Eles levantavam do canto deles para ficar de pé e ver o que o outro estava fazendo, então... foi muita curiosidade, eles misturavam muita cor, eu auxiliei nos procedimentos, como usar os pincéis, limpar, eu chegava em casa com as mãos cheias de tinta. (INFORMAÇÃO VERBAL) ${ }^{8}$

${ }^{8}$ Manifestação verbal da professora no último encontro do grupo focal ocorrida em 03 de julho de 2018. 
A utilização da obra dos artistas surge como um disparador, como fonte geradora de outras imagens. Principalmente na Educação Infantil, consideramos de extrema importância a criança ter espaço para viver a arte na escola. Ter oportunidade para fazer, criar, experimentar processos, explorar materiais e poder se expressar.

Figura 4 - Sol vermelho

Fonte: Juan Miró (1950)

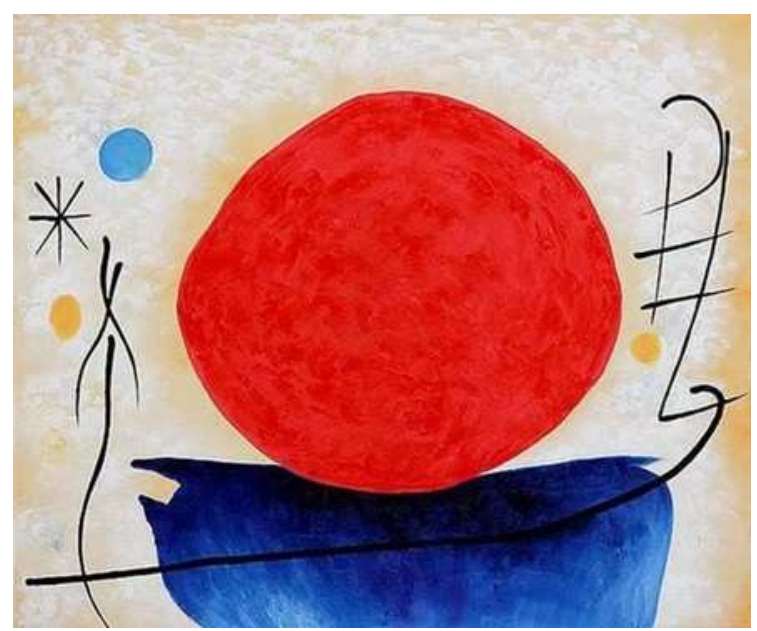

Figura 5 - O Galo

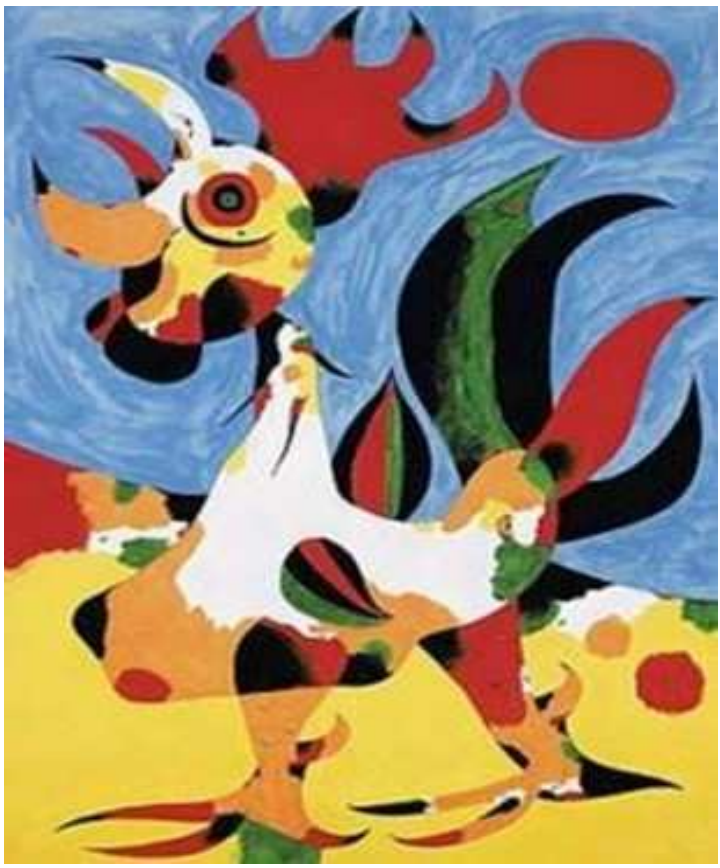

Fonte: Juan Miró (1939)

Para a criança, a experiência estética está associada à prática, ou seja, a uma vivência artística que poderá ser transformadora. Dessa forma, o potencial criativo e de expressão 
ganha significado relevante na medida em que ele está associado à experiência cultural e sua ação será articulada por meio de atividades que demandem os cinco sentidos e da materialidade que lhe é disponibilizada, como é possível vermos nos desenhos dos alunos a seguir.

Figura 6 - Desenhos dos alunos

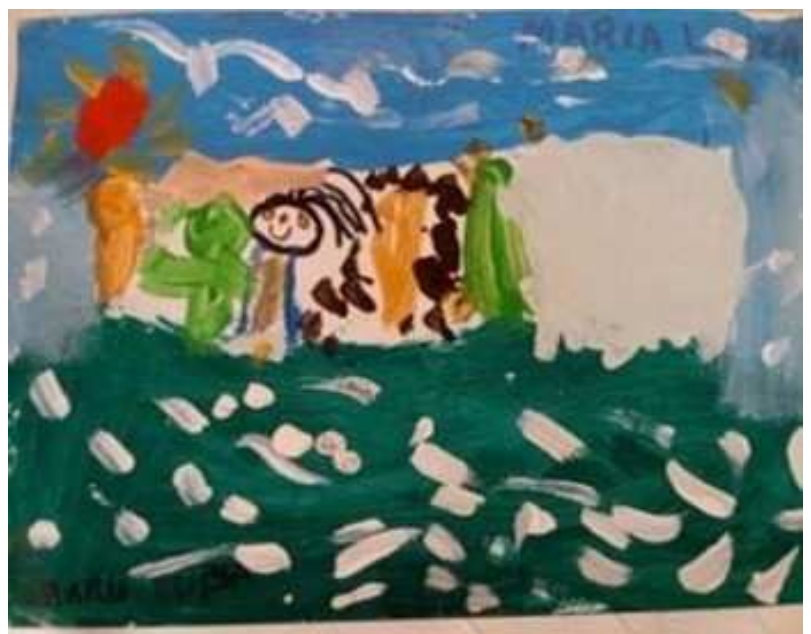

Fonte: Acervo das pesquisadoras

Figura 7 - Desenhos dos alunos

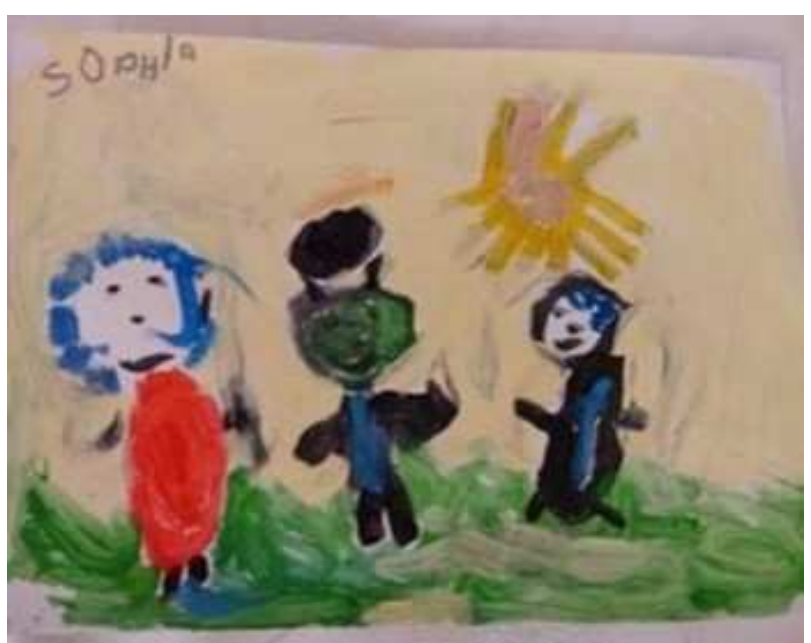

Fonte: Acervo das pesquisadoras

Figura 8 - Desenhos dos alunos 


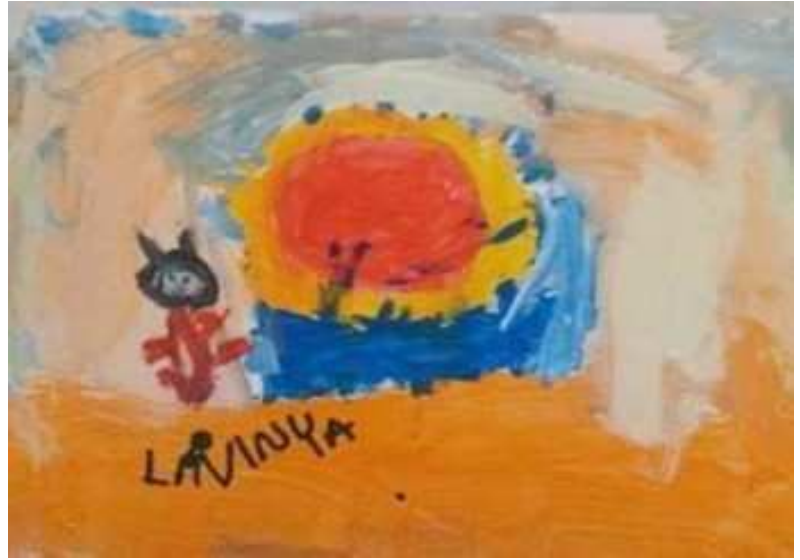

Fonte: Acervo das pesquisadoras

Figura 9 - Desenhos dos alunos

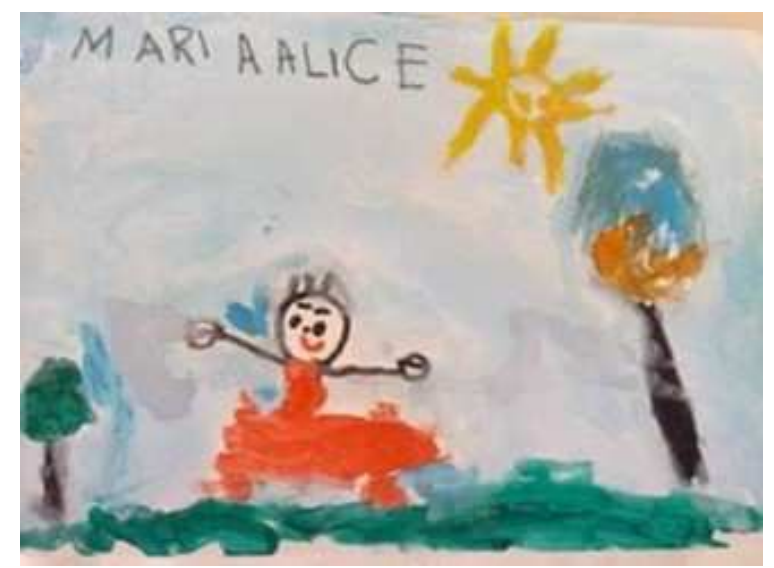

Fonte: Acervo das pesquisadoras

Observando as pinturas realizadas pelas crianças, percebemos que existem elementos das imagens disparadoras, tais como o sol da obra Sol vermelho, de Juan Miró (1950), e os três gatos de Família de gatos, de Aldemir Martins (2003). No entanto, as pinturas das alunas não estão iguais as obras e não são iguais entre elas, o que denota que elas tiveram liberdade para criar e expressar seus desejos sobre o que queriam representar. Conseguimos ver aqui a criança como autora e produtora de sua obra, assim como observar o crescimento da professora Mi. ao relatar sobre a relevância do grupo focal na sua prática.

M.I.: Eu gosto e sempre gostei de artes, mas é aquela parte que eu tenho mais dificuldade... tinha, né? De trabalhar com os meus alunos, eu achava que tinha que sair alguma coisa, tinha que ter forma, então foi muito importante porque eu aprendi que não, pode ter forma se eles quiserem dar a forma, do contrário eles podem só misturar as cores, até porque tem a pintura abstrata, eles precisam criar. Para mim, ficou claro quando eu for trabalhar com pintura, eu não sabia. Outra coisa... materiais que eu não conhecia, e não sabia que podia usar, e eu tenho certeza que daqui para frente o meu trabalho vai ser melhor e eu gostaria de estudar mais, porque eu acho que a gente só começou, tem muita coisa para aprender. Os textos a gente encontra, material a gente encontra, mas a troca de experiências não 
tem nos textos, ouvir o outro, a prática, ver como a outra fez, a gente aprende um pouquinho com cada uma, sem perceber a gente vai aprendendo. (INFORMAÇÃO VERBAL) ${ }^{9}$

Dentro desse contexto do grupo focal, a professora apresentou suas percepções e o que foi relevante para ela como pessoa e para o seu exercício em sala de aula: "Foi muito importante esse espaço de discussão, pois, ao longo da nossa prática, a gente vai se afastando do mundo acadêmico, e por mais que a gente tenha acesso à formação continuada, ela não é voltada especificamente para a arte, que é um campo abrangente e que precisa ser estudado" (informação verbal). A professora se referiu a coisas que estavam adormecidas, a um saber que ficou guardado e precisou ser resgatado - cada pessoa tem um repertório que, às vezes, fica perdido em um cantinho da memória. $\mathrm{O}$ exercício de olhar para dentro e se reconhecer como produtor de cultura é essencial para a formação do docente, principalmente quando se é professor na Educação Infantil com a missão de trabalhar o conteúdo Arte com as crianças e dos diferentes sentidos que as ações pedagógicas e as interações entre os pares podem sinalizar naquele contexto de aprendizagem.

Diante de tamanha responsabilidade é preciso formar uma rede de investimento cultural na formação dos professores, no trabalho colaborativo, para que possamos criar parcerias para aprender e literalmente efetuar o fazer juntos.

\section{Conclusão}

Ao finalizar, a pesquisa se revelou como um indicativo da necessidade de refletirmos sobre a formação estética do professor pedagogo que atua na Educação Infantil, e que responde pelo conhecimento em artes na sala de aula.

Observamos que é imperativo mudar o olhar estereotipado do adulto/professor para as artes visuais na Educação Infantil, possibilitando que as crianças se expressem e desenvolvam o senso crítico e estético, a autonomia, a sensibilidade e a imaginação criadora, além da sua expressão autoral. A vivência artística e estética quando significativas para a criança potencializam sua singularidade e constituem a sua subjetividade, ampliando o seu repertório cultural.

Ao fim e ao cabo, ensejamos que a arte, em todas as suas linguagens e manifestações, possa despertar a potência de ser quem somos, que ela esteja presente na escola e na vida sempre, ensinando-nos a olhar o mundo, e que o professor seja o guia que conduz esse olhar da criança em busca do seu próprio maravilhamento.

\footnotetext{
${ }^{9}$ Manifestação verbal da professora no último encontro do grupo focal ocorrida em 03 de julho de 2018.
} 


\section{REFERÊNCIAS}

ALMEIDA, C. M. C. Concepções e práticas artísticas na escola. In: FERREIRA, S. (org.). O Ensino das Artes: construindo caminhos. 10 ed. Campinas: Papirus, 2012.

BARBOSA, A. M. (org.). Arte/educação contemporânea. Consonâncias internacionais. 3. ed. São Paulo: Cortez, 2010.

BARBOSA, A. M. A imagem no ensino da arte. 9. ed. São Paulo: Perspectiva, 2014.

BARBOSA, A. M. Arte/educação é arte e pedagogia. In: LIMA, S. P. F. Arte e pedagogia: a margem faz parte do rio. São Paulo: Porto de Ideias, 2017

BUORO, A. B. O olhar em construção, uma experiência de ensino e aprendizagem da arte na escola. São Paulo: Cortez, 2000.

CUNHA, S. R. V. (org.). As artes no universo infantil. Porto Alegre: Mediação, 2014.

DEWEY, J. Arte como experiência. São Paulo: Martins Fontes, 2010.

DUARTE JUNIOR., J. F. Por que arte- educação? 22. ed. Campinas: Papirus, 2012.

GATTI, B. A. Grupo focal na pesquisa em ciências sociais e humanas. Brasília: Líber Livro, 2005.

IAVELBERG, R. Arte, infância, formação docente e cultura na escola. In: CUNHA, S. R. V.; CARVALHO, R. S. (org.). Arte contemporânea e educação infantil: crianças observando, descobrindo e criando. Porto Alegre: Mediação, 2017.

IERVOLINO, A. S.; PELICIONI, M. C. F. A utilização do grupo focal como metodologia qualitativa na promoção da saúde. Rev. Esc. Enf. USP, São Paulo, v. 35, n. 2, p. 115-121, jun. 2001.

MARTINS, A. (Obra) O Galo. 1997. Disponível em: http://obviousmag.org/pintoresbrasileiros/aldemir_martins/aldemir-martins-e-a-renovacao-da-arte-cearense.html\#: :text=. Acesso em: 10 ago. 2020.

MARTINS, A. (Obra) Os Gatos, 2003. Disponível em: http://obviousmag.org/pintoresbrasileiros/aldemir_martins/aldemir-martins-e-a-renovacao-da-arte- cearense.html. Acesso em: 10 ago. 2020.

MARTINS, M. C; PICOSQUE, G; GUERRA, M. T. Teoria e prática do ensino de arte, a língua do mundo. São Paulo: FTD, 2009.

MEIRA, M. R. Filosofia da criação: reflexões sobre o sentido do sensível. 3. ed. Porto Alegre: Mediação, 2009. 
MIRÓ, J. (obra) O Galo. 1939. Disponível em: https://artsandculture.google.com/artprojector/6gECVMFVB7E05w?hl=PT-BR. Acesso em: 10 ago. 2020.

MIRÓ. J. (obra) O Sol Vermelho. 1950. Disponível em:

https://www.pinterest.com.mx/pin/17592254773703875/. Acesso em: 10 ago. 2020.

OSTETTO, L. E. Educação infantil e arte: sentidos e práticas possíveis. In: ZAMBELLO, S. P. et al. (coord.). Caderno de formação: formação de professores, educação infantil, princípios e fundamentos. São Paulo: Cultura Acadêmica, 2011. p. 27-39.

PILLAR, A. D. (org.) A educação do olhar no ensino de artes. Porto Alegre: Mediação, 2014.

PILLAR, A. D. A educação do olhar no ensino de artes. In: Barbosa, A. M. (org.)

Inquietações e mudanças no ensino de arte. 7 ed. São Paulo: Cortez, 2012.

READ, H. A educação pela arte. 2. ed. São Paulo: Martins Fontes, 2016.

VIGOTSKI, L. A imaginação e a arte na infância. Lisboa: Relógio D’Agua Editores, 2009.

\section{Como referenciar este artigo}

MARTINS, S. A.; MATTOS, M. F. S. C. G. Experiências significativas em artes visuais na educação infantil. Revista Ibero-Americana de Estudos em Educação, Araraquara, v. 16, n. 3 , p. 2199-2220, jul./set. 2021. e-ISSN: 1982-5587. DOI: https://doi.org/10.21723/riaee.v16i3.14487

Submetido em: 23/11/2020

Revisões requeridas em: 24/02/2021

Aprovado em: $12 / 03 / 2021$

Publicado em: 01/07/2021 